\title{
Integration of Case Study and Digital Technologies in Physics Teaching Through the Medium of a Foreign Language
}

https://doi.org/10.3991/ijet.v15i04.11699

Sherzod Ramankulov ${ }^{(凶)}$, Elmurat Dosymov, Torebay Turmambekov, Dilmurad Azizkhanov, Sherzod Kurbanbekov, Sattarbek Bekbayev Khoja Akhmet Yassawi International Kazakh-Turkish University, Turkestan, Kazakhstan sherzod.ramankuloveayu.edu.kz

\begin{abstract}
The purpose of this study is to determine the possibilities of digital technologies and case study method in the development of creativity of the future teachers in physics teaching through the medium of a foreign language. The Akhmet Yassawi International Kazakh-Turkish University has created computer models of various physical processes and phenomena on the basis of Optics in English training course and has developed a method of their application. Since English opens the way to the formation of creativity, we have evaluated the effectiveness of the methodology we have developed, through the evaluation of creativity. The nearly 73 students were engaged in an experiment presented below in chronological order. The reliability of results obtained at the beginning and at the end of forming stage for each criteria of creativity, as well as for the integral indicator is provided by Pearson criterion $\chi^{2}$. At the beginning of the experiment it is seen that $\chi^{2}{ }_{\exp }<\chi^{2}{ }_{t g}$ that means there are no differences between the development level of students' creativity from both experimental and target groups. At the end of the experiment $\chi^{2}{ }_{\exp }>\chi^{2}{ }_{t g}$, that means there are significant differences in the development level of students' creativity.
\end{abstract}

Keywords-Case-study method, digital technologies, educational forms and techniques, language integrated learning, physics teaching.

\section{$1 \quad$ Introduction}

The revision of specialists' training system by the world's leading pedagogical universities resulted in new comprehensive specialties [1], as well as system of supplementary education in the field of professional communication [2], that was expected from the humanitarization of physical and natural science education and also reflects the need of society for specialists who are ready to work in the foreign language medium [3].

The second language-integrated education of future Physics teachers and teaching of foreign Physics students in English in the world's universities are different meth- 
odological directions for any Physics teachers: both phenomena consider Physics teaching in a second language; however, one problem is the same: development Physics manuals in English as a second language [4].

At the moment, the greatest attention of those who studies language integrated learning (LIL) is paid to the stage of pre-university training of foreign students in the world: the features of teaching approaches in other content subjects are considered [5]. However, professionally oriented LIL and language-integrated competence of students in the universities were not also overlooked. Despite the lack of information concerning application of the language integrated method in Physics teaching there is the phenomenon like Physics teaching in a second language which is obviously considered as a single methodological issue.

While studying foreign literature, it should be noted that CLIL can be used as the latest technology for the development of subject-language competence.

The authors defined the subject-language competence as the Ability to selfeducation, the ability to make decisions on their own, adaptability to new conditions, teamwork skills, the ability to cope with stress, to communicate in a foreign language within a given thematic field.

At a time when the importance of the topic of our study is of particular importance for the country, there is a noticeable lack of research in this area. The lack of research in the field of development of subject-language competence in the teaching of natural subjects, in particular, physics, unformed systematization of teaching didactics, lack of advanced technologies, textbooks and effective methods create difficulties for the development of this direction. The only way to overcome these difficulties is to combine IT-based management of education with Physics teaching in English.

\subsection{Literature review}

The studies of Prather E., Rudolph A., \& Brissenden G. and Klein can be considered when talking about students' teaching in Physics through the digital technologies.

When a foreign language is used to teach certain subjects in this case there is one direction with the use of an intermediary language in which the language of teaching is a foreign language not only for student but also for a teacher. In our country and abroad, English is most often used as the intermediary language.

The second language integrated teaching is widely used in national and international high schools and according to studies conducted [6] this is because of attraction of such English-based training programs from commercial point of view as well as personnel promotion, growth of the university competitiveness at an educational market, bring $\mathrm{PhD}$ expertise abroad etc. According to the research carried out by the European Academic Cooperation Association, the European universities are encouraged to develop English-based training programs because of attracting both foreign and local students (providing the national labor market with highly qualified personnel with international experience)[7].

The second language integrated teaching of local and foreign students is seen to be insensitive by researchers but the interest in this matter has recently increased signifi- 
cantly. At the same time, according to Al-Shukri, second language integrated learning at national universities increases the level of requirements for foreign students because there is no language barrier between a student and a teacher; it develops internal competition and strengthens learning motivation as well as attracts teachers with fluent English[8]. In such circumstances, learning of future teachers in the specialty Physics and English is seen as training of world-class specialists [9].

Renata Elsakova, Nadezhda Kuzmina, Daria Kochkina applied smart technologies in the process of English teaching, such as different language learning platforms ( $\mathrm{E}$ modo, TEDed), social networks (VKontakte, Facebook), and a new online language development course, "English for General Purposes" which was implemented through the Moodle (the university corporate learning management system). The analyzed results and the drawn conclusions indicate that the integration of smart technologies allows to boost foreign language skills and encourage motivation [10].

Let's take a closer look at the approaches used both in training foreign students in a second language in our country and in training our students to make them able to work in a second language medium. It should be noted that an important feature of the CLIL is a simultaneous learning of the subject and language of instruction, i.e. the implementation of educational activities in conditions of imperfect knowledge of the language of instruction. The quality of training of foreign students in our country is directly dependent on the theoretical study of this issue, which is not reduced to the methodology of learning a foreign language, or to the methodology of teaching certain disciplines in pure form. In our opinion, the methodology of Physics teaching in second language should be considered as a complex of tasks and should integrate the methodology of Physics teaching with certain aspects of the methodology of English teaching [11].

The problem of training Bachelors of Education in Natural Science in universities is seen to be relevant with a focus, on the one hand, to improve the scientific and methodological training of future Physics teachers, on the other hand, aimed at the widespread use of digital technologies in teaching, management of the educational process.

It is necessary to start fundamental research in order to make future Physics teachers ready for the use of digital technologies. An integral model of Physics teacher with additional specialization in computer science, based on an accurate forecast of trends in the development of the education system in general and computer science in particular, is a global problem, and its relevance is obvious.

We took into account another important fact that in the current socio-economic conditions of the development of society one of the urgent tasks of training is the development of personal qualities of future teachers, the development of their creative thinking, creative potential and value orientations [12]. We believe that the use of new methods as a case study in Physics teaching, in particular, in language-integrated Physics teaching is promising for solving these problems. It is needed to join interactive educational methods as case study with digital technologies while languageintegrated Physics teaching. Their use in today educational system is stipulated by several factors. First, thanks to social and economic achievements, many universities have computers. The number and quality of ready-made software products in Physics 
help to realize various learning technologies. Secondly, computer modeling allows to obtain dynamic visual illustration not only actually observed physical processes and phenomena but those are unobservable in a real experiment and also allows for more flexibility in computational physical experiments and solving different experimental tasks in English. The computer along with update support equipment is used to realize various studied processes at a high level.

In his efforts the U.S. researcher Becker examines features of digital technologies in Physics learning. Mr. Becker proposes to change the way of use of digital technologies in Physics learning to meet actual requirements. Only then, it will be possible to improve the quality of students' knowledge in Physics [13].

Darmaji, Dwi Agus Kurniawan, Astalini,Artha Lumbantoruan, Sofia Christine Samosir believe that using the website as a learning tool in physics practicum broadly gives users access without downloading additional applications that are burdensome to the device[14].

C. Angell, O. Guttersrud, E. Henriksen and A. Isnes [15] in their efforts pay attention on the approaches in Physics teaching via digital technology. Their main concept is that Physics is very interesting although complicated science and teacher with students should improve the methodology of Physics teaching in accordance with modern requirements, to introduce information technology in the process of timely learning.

As well as some foreign scientist such as Klein (2014), proposed to increase the interest of students by animated analysis of physical phenomena, using i-pad or a computer as a means of experiment.

Papadakis, St., Kalogiannakis, M., Rudolf, A., Leimin, S., Prather, E, showed the importance of case study method in teaching practice for natural sciences based on the specifics of digital technologies and Mobile educational applications [16-18].

The thesis use of information and communication technologies in the development of creative potential of future Physics teachers at the university written by A. Amiraliev [19] considers development of creative potential of future Physics teachers using ICT and case study at the universities.

In the case-study the key element is undoubtedly the case which also has a number of characteristic features that are important for this study. Based on the analysis of scientific papers which explain the meaning of "case" [20], its characteristic features in the context of foreign language learning were identified and generalized: the case, consisting of authentic texts, has a communicative, dynamic, practical nature, since it involves the definition, discussion and joint search for solutions to urgent problems related to professional activities, and also has an interdisciplinary nature, since it is an information complex, which includes a range of related conditions from economic to socio-political ones. It is important to note that to solve the case it is necessary to take into account the full range of related conditions, to take into account relationship between presented areas of knowledge to obtain a complete picture and make the most correct decision. However, it should be emphasized that the case-study method is a tool to integrate related subject in second language medium and makes it possible to organize the process of the CLIL taking into account specifics of future professional activity by focusing on the formation of key skills of future specialist and also ena- 
bles the student to see the diversity of interdisciplinary connections, because it is complex.

However, the use of ICT and cases is insufficiently covered in the development of creativeness of Physics teachers in the CLIL process.

The relevance and urgent need for practice in improving educational process to make future teacher ready for creative professional activity led to the choice of the line of our study.

\subsection{Research focus}

Despite this, second language integrated teaching of future educators and school Physics teachers through the digital technologies has been formed not as a unite system, but is still considered as an individual proposal.

Nevertheless, above studies are about the use of information and communication technologies in teaching of high students, but unfortunately, a fundamental scientific solution to the problem of implementing the development of subject-language competence of students in the conditions of IT-based management of education has not been found yet. There is a contradiction between the need to use digital technologies for the development of subject-language competence of students, the need for new technologies, methodological and computer software for its implementation and the lack of research in educational system based on the development of subject-language competence of students through the use of digital technologies.

The search for solution to this contradiction is mainly featured our research, that is, the development of subject-language competence in the process of Physics teaching in the way of IT-based management of education.

\section{Research Methodology}

\subsection{General background}

The following methods were used while study implementing:

- Analysis of methodological, philosophical, psychological, pedagogical and methodical literature

- By means of various questionnaire, tests and reviews to elicit to what extent English is in-demand in schools of Turkestan region and find out the level of English proficiency

- Review of advanced language acquisition technologies; consultations with scholars abroad

- Analysis of case-study method in Physics teaching in English as second language

- Review of IT education, elements of robotics and electronic digital resource

- Selection of 3D and 4D computer programs needed to create digital resources

- Creation of methods to build subject-language competence of future educators and school Physics teachers 
- Implement field activities, develop tests, using mathematical and statistical methods

\subsection{Participants}

The nearly 73 students were engaged in an experiment at International kazakhturkish university named After Kh.A.Yassawi (Turkestan, Kazakhstan) presented below in chronological order. 36 students at target (TG) and 37 students at experimental group (EG). As part of the experiment, it was necessary not only to ensure the implementation of laboratory work in English and/or reports on the results of laboratory work in English by creating a foreign-language didactic environment and the development of foreign-language subject communication in the experimental group by the introduction of special teaching methods, but also to compare the results of training with a target group.

\subsection{Instrument and procedures}

The Akhmet Yassawi International Kazakh-Turkish University has created computer models of various physical processes and phenomena on the basis of Optics in English training course and has developed a method of their application. They have also elaborated an elective training course on the application of computer models and demonstration of various physical processes and phenomena Application of computer models and demonstration in Optics. The teachers' team has set up a curriculum on Optics course. It covers 135 hours per one semester totally including 90 hours of class work, that is divided into 15 hours of lectures, 15 hours of practice, and 15 hours of laboratory works as well as 45 hours take students' individual work. At the end of the semester student should take an exam. The teachers' staff has also outlined syllabus for Physics training course on credit transfer educational system, introduced it in the educational plan and placed on the website of the University (www.ayu.edu.kz).

This training course can be used by students studying Physics, Information technologies, Mathematics, Information systems, Automation and control. The authors note that this manual can be used by the teachers at the institutes, colleges, schools, gymnasiums and lyceums who teach in classes with in-depth study of Physics.

Students need to pass an exam at the end of the training course on Optics and they must to explain theoretical questions and solve a physical problem in English, and one of the criteria for successful completion of the exam is to show their speaking skills in English in the field of Physics.

Since English opens the way to the formation of creativity, we have evaluated the effectiveness of the methodology we have developed, through the evaluation of creativity. 


\section{Research Results}

\subsection{What are the pedagogical possibilities of digital technologies and case- study method?}

To successfully apply digital technology in language integrated Physics teaching it is required to clearly understand basic principles and techniques that contribute to the strengthening of future teachers' intellectual capabilities.

The structure and content of future teachers' professional training are undergoing significant changes today. Social order of training in modern professional school is focused on the development of thinking, creative inclinations of students, and their involvement in independent search activity, familiarization with the methods of scientific knowledge, formation of the ability to apply knowledge in new conditions. One of the ways to implement this direction is to organize students' productive and creative activity which, in turn, is a condition for the formation of their professionalism.

The problem of our research can be formulated as follows: what are the pedagogical possibilities of ICT and case-study method in the development of future teachers' creativity and appropriate educational conditions for their use in future teachers' training. Our research is aimed to find the solution of this problem. Below we offer didactic conditions for improving language integrated Physics teaching (Table 1).

Table 1. Didactic conditions for Physics teaching in English.

\begin{tabular}{|l|l|}
\hline \multicolumn{2}{|c|}{ Prerequisites for the development of teaching physics in english } \\
\hline \multicolumn{1}{|c|}{ Prerequisites } & \multicolumn{1}{c|}{ Results } \\
\hline $\begin{array}{l}\text { To give theoretical underpinning } \\
\text { of content and language (English) } \\
\text { competence development of future } \\
\text { teachers and school physics teach- } \\
\text { ers by means of new information } \\
\text { technologies use }\end{array}$ & $\begin{array}{l}\text { Results of specified tasks solutions differ in a clear idea of theoretical } \\
\text { bases of new information technologies use in content and language } \\
\text { competence development. } \\
\text { To set up didactic system content and language competence develop- } \\
\text { ment of future teachers and school physics teacher; } \\
\text { As a research result of the specified task the system of advanced tech- } \\
\text { nologies of physics in English development will be created and intro- } \\
\text { duced in educational process. }\end{array}$ \\
\hline $\begin{array}{l}\text { Definition of General Physics } \\
\text { study course content by means of } \\
\text { information technologies }\end{array}$ & $\begin{array}{l}\text { According to the didactic system created during solution of this task } \\
\text { electronic textbooks and manuals will be published and introduced in } \\
\text { schools and higher education institutions. Also the maintenance of the } \\
\text { organization and holding facultative occupations at school will be } \\
\text { defined. }\end{array}$ \\
\hline $\begin{array}{l}\text { The organization of upgrade } \\
\text { training course for regional } \\
\text { schools physics teachers }\end{array}$ & $\begin{array}{l}\text { Physics teachers at the schools of Turkestan city department of educa- } \\
\text { tion will complete upgrade training course, based on the best foreign } \\
\text { practices, and will examine the maintenance of facultative lessons. }\end{array}$ \\
\hline $\begin{array}{l}\text { Start of the portal (website) "Phys- } \\
\text { ics education in English" in public } \\
\text { and republican level; }\end{array}$ & $\begin{array}{l}\text { Creation of electronic educational resources (electronic textbooks and } \\
\text { multimedia programs, demonstration and virtual computer models), } \\
\text { release of the manuals based on the advanced foreign methods and } \\
\text { definition of use methods in the course of physics education. }\end{array}$ \\
\hline $\begin{array}{l}\text { Ensuring introduction of electronic educational resources and manuals at the rate of the general physics in } \\
\text { republican schools educational process. Carrying out skilled and experimental works, creation of tests, use } \\
\text { of mathematical and statistical methods }\end{array}$ \\
\hline
\end{tabular}


Thus, below we consider the method of using these didactic conditions in any form of training.

At the university a lecture keeps on using to introduce new educational material, there is a problem of using digital technologies to improve the efficiency of lectures. According to D. Matros, D. Polev, N. Melnikova, N. Sokolova and A. Skripkin, lectures-presentations are one of the main opportunities for digital tools to be used in an educational process and the main idea behind of this is in applying computer technologies for visual presentation of the most important information on slides (texts, formulas, drawings, tables, graphic materials, etc.) [21].

\subsection{Language learning e-textbooks}

We have created an e-textbook on Optics, which provides for the use of an interactive mode for tutoring, performing training tasks, creative exercises and checking the level of students' subject knowledge in English. In this tutorial we have developed computer models of optical phenomena in the form of animation, such as wave properties of light - interference, diffraction, polarization, and corpuscular properties of light - photoelectric effect, Compton Effect. Below are some of these models (Fig.1).

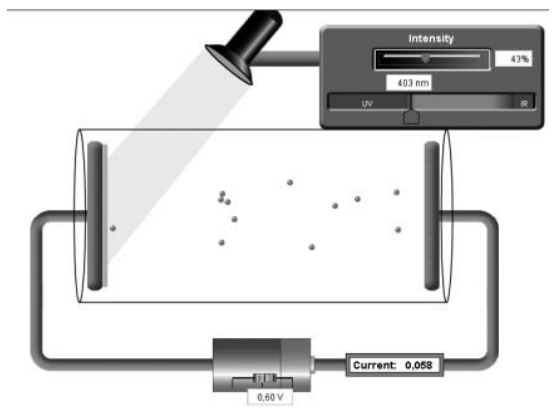

(a)

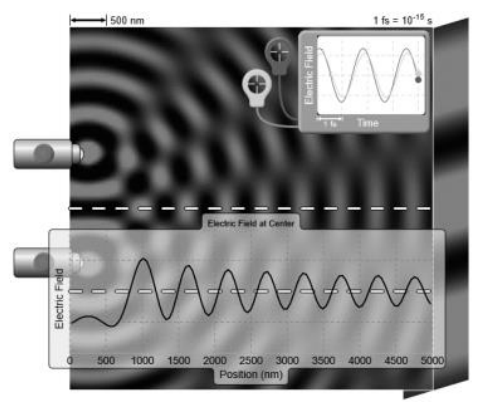

(b)

Fig. 1. Computational models in Optics. (a- photoeffect, $b$ - interference)

During the workshops we try to apply creative tasks that make students think critically and use additional literature. To increase students' creativity and individual work we have developed a workbook in Optics with creative tasks. The workbook includes different cases, puzzles, experiment-based tasks and various tests. Herewith are some examples from our workbook:

\section{CASE \#1}

Maksat and Raushan decided to make a resistor for Physics. Maksat took a copper wire and Raushan took an iron wire.

- That's not a good idea to use an iron wire, a conductor is better to make from a copper wire, it is more valuable, - Maksat said. 
- I think the copper wire is hardly suitable because the resistance will be very low, Raushan said.

- Well, it depends on what wire is to take! - Maksat chuckled. - Mine's better.

\section{Questions to the case}

- Who of friends is right?

- What characteristics should have the wire to make a resistor

- How to calculate the resistance of a resistor made of simple wire?

- How to check if you are right?

Table 2. Example on Optics for students.

\begin{tabular}{|c|c|c|c|c|}
\hline Property & Example & Waves & Particles & Notes \\
\hline $\begin{array}{l}\text { Reflaction, } \\
\text { Refraction }\end{array}$ & $\begin{array}{l}\gamma=\alpha \\
n=\frac{\sin \gamma}{\sin \beta}\end{array}$ & + & + & 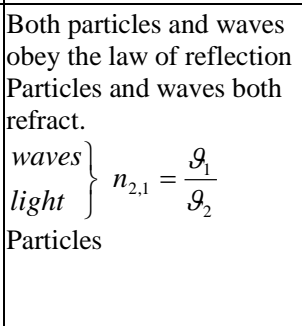 \\
\hline Dispersion & & + & & $\begin{array}{l}\text { Waves naturally do this, } \\
\text { particles do not }\end{array}$ \\
\hline Interference & -11 & + & & $\begin{array}{l}\text { Waves naturally do this, } \\
\text { particles do not }\end{array}$ \\
\hline
\end{tabular}
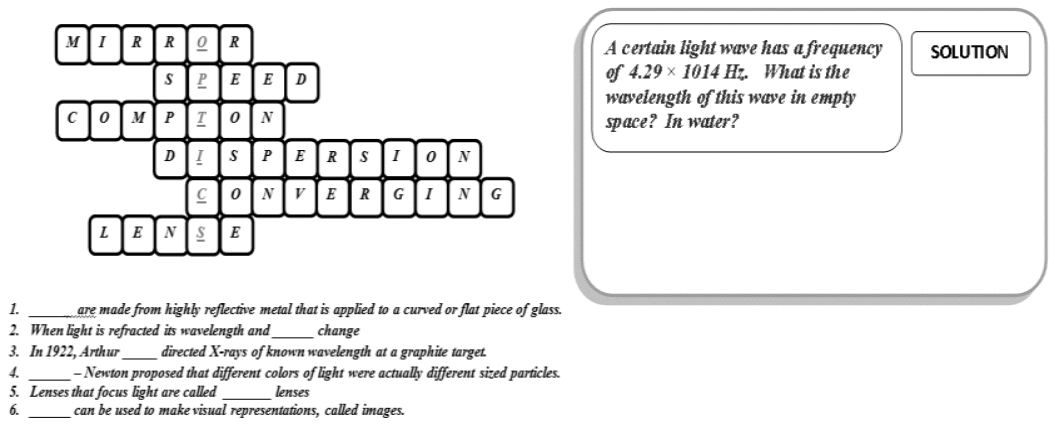

Fig. 2. Crossword from a students' workbook in Optics 
Every teacher from the Department of Physics is also able to use full interactive Open physics course which includes more than 80 virtual laboratory complexes, video recordings of experiments with voice explanations. They provide options for changes in a wide range of initial parameters and conditions of experiments, varying their time scale, as well as modeling situations that are not available in real experiments.

Below is a fragment from a virtual laboratory work identifying the radius of curvature of the lens using Newton's ring" (Figure 3).

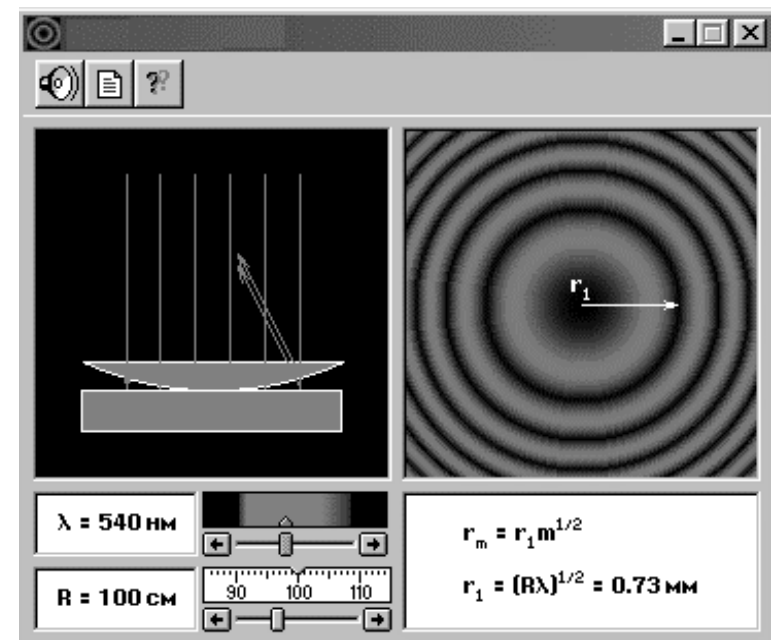

Fig. 3. A fragment from virtual laboratory work.

Experimental verification of the effectiveness of educational and methodical complex in second language-integrated Physics learning is quite a difficult task, because usually such an experiment is to compare a new textbook with existing ones.

\subsection{Comparison of the creativity level among future Physics teachers}

Since English opens the way to the formation of creativity, we have evaluated the effectiveness of the methodology we have developed, through the evaluation of creativity.

Monitor of the level of students' creativity involves the use of special techniques. There are a lot of scientific approaches to the problem of creativity research (J. Gilford, E. Torrence, D. L. Johnson and E. Tunick).

For our experiment, the most appropriate method is the method of creativity monitoring, proposed by E. P. Torrance [22], which is currently recognized as the most reliable and valid in comparison with other methods and is used for different age groups.

The table below lists some criteria of creativity: 
Table 3. General formation structure of future Physics teachers' creativity.

\begin{tabular}{|l|l|l|}
\hline \multicolumn{1}{|c|}{ Components } & \multicolumn{1}{|c|}{ Criteria and indicators } & \multicolumn{1}{|c|}{ Levels } \\
\hline Fluency Thinking & $\begin{array}{l}\text { - quickly perform creative tasks } \\
\text { - able to solve tasks fast } \\
\text { - able to quickly recognize the new } \\
\text { - able to act promptly } \\
\text { - able to create several thoughts corresponding } \\
\text { to the tasks; resourceful thoughts }\end{array}$ & $\begin{array}{l}\text { Low } \\
\text { Average } \\
\text { High }\end{array}$ \\
\hline Flexible Thinking & $\begin{array}{l}\text { - tend to practice } \\
\text { - be flexible to new problems } \\
\text { - tend to solve the problem } \\
\text { - be loyal to discussions } \\
\text { - think beyond the borders of the task } \\
\text { - be able to find more than one solutions } \\
\text { - be able to give more than one right answers } \\
\text { to new problem }\end{array}$ & $\begin{array}{l}\text { Low } \\
\text { Average } \\
\text { High }\end{array}$ \\
\hline Original Thinking & $\begin{array}{l}\text { - have some original thoughts while imple- } \\
\text { menting the task } \\
\text { - be able to do the task by themselves } \\
\text { - able to be sensible } \\
\text { - offer original solution } \\
\text { - use some individual elements in solution of } \\
\text { new problem }\end{array}$ & $\begin{array}{l}\text { Low } \\
\text { Average } \\
\text { High }\end{array}$ \\
\hline
\end{tabular}

Fluency, flexibility and originality of thinking were monitored by E. Torrance technique where verbal Physics-adopted subtests were used. The scores students had obtained passed through the quantitative and qualitative analysis. Table 4 shows changes in distribution of the level of creativity among students in target (TG) and experimental groups (EG) at the beginning and at the end.

Table 4. Comparison of the creativity level among future Physics teachers before and after experiment.

\begin{tabular}{|l|l|c|c|c|c|}
\hline \multirow{2}{*}{ Index of creativity } & \multirow{2}{*}{ Level } & \multicolumn{2}{|c|}{ Before experiment } & \multicolumn{2}{c|}{ After experiment } \\
\cline { 3 - 6 } & & $\boldsymbol{T G}$ & $\boldsymbol{E G}$ & $\boldsymbol{T G}$ & $\boldsymbol{E G}$ \\
\hline \multirow{3}{*}{ Fluency Thinking } & High & 6 & 7 & 5 & 12 \\
& Average & 18 & 14 & 21 & 20 \\
& Low & 13 & 15 & 11 & 4 \\
\hline \multirow{3}{*}{ Flexible Thinking } & High & 10 & 10 & 5 & 14 \\
& Average & 14 & 9 & 21 & 10 \\
& Low & 13 & 17 & 4 & 11 \\
& Original Thinking & 6 & 3 & 11 & 13 \\
& High & - & - & 22 & 12 \\
\hline
\end{tabular}




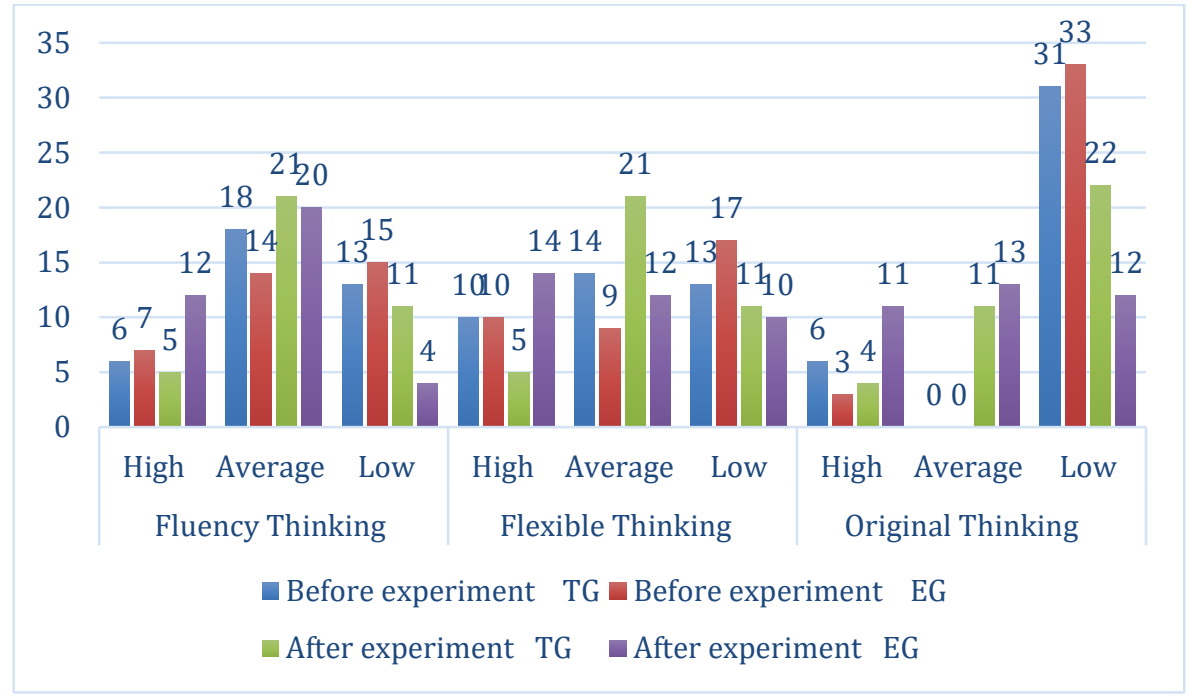

Fig. 4. Dynamics of students' creativity.

Comparative indicators on creative properties of future Physics teachers before and after the experiment:

According to the data shown in Table 4, it can be noted that creativity is being developed uneven. In particular, 55\% of students in experimental groups have an average level of thinking fluency. In relation to the originality of thinking at the beginning of the experiment, students showed low and high levels of development, i.e. in the course of the experiment the students either did not exercised originality of thinking at all, or gave one answer, which could be considered as original. In general, experimental group has demonstrated higher level of creativity.

Thus, it can be seen that e-teaching aids and virtual laboratory complexes created in the process of our study improve the quality of knowledge and professional training, contribute to the formation of creative thinking of future Physicists by combining theory and practice.

\section{Discussion}

The reliability of results obtained at the beginning and at the end of forming stage for each criteria of creativity, as well as for the integral indicator is provided by Pearson criterion $\chi^{2}$ and Student's t-test. To compare the distribution of students by levels of creativity in target and experimental groups the following hypotheses were formulated: N0 - no significant differences in the levels of creativity; N1 - there are significant differences.

Table 5 shows the values of Pearson test $\chi^{2}$ эксп on tested qualities on a quasiprofessional level of physics teaching at the beginning and at the end of forming 
stage. According to the table of critical values for originality of thinking $\%$

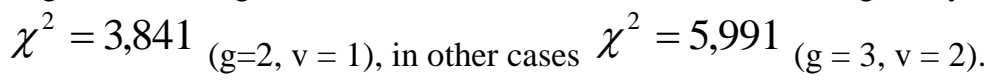

Table 5. Values $\chi^{2}{ }_{\text {эксп }}$ at the beginning and at the end of forming stage.

\begin{tabular}{|l|c|c|}
\hline \multicolumn{1}{|c|}{ Creative qualities } & Before experiment & After experiment \\
\hline Fluency Thinking & 0,706 & 6,160 \\
\hline Flexible Thinking & 1,606 & 6,753 \\
\hline Original Thinking & 1,049 & 6,362 \\
\hline
\end{tabular}

At the beginning of the experiment, it is seen that $\chi^{2}$ exp $<\chi^{2} \operatorname{tg}$ that means there are no differences between the development level of students' creativity from both experimental and target groups (hypothesis $\mathrm{H} 0$ ). At the end of the experiment $\chi^{2}$ exp $>\chi^{2}$ tg , that means there are significant differences in the development level of students' creativity (hypothesis H1).

Values of t-criteria texp and ttg at the beginning and at the end of the experiment are shown in Table 6.

Table 6. Values of t-criteria texp and ttg at the beginning and at the end of the experiment.

\begin{tabular}{|l|c|c|c|c|}
\hline \multirow{2}{*}{ Creative qualities } & \multicolumn{2}{|c|}{$\mathbf{t}_{\exp }$} & \multicolumn{2}{c|}{$\mathbf{t}_{\mathrm{g}}$} \\
\cline { 2 - 5 } & Before experiment & After experiment & Before experiment & After experiment \\
\hline Fluency Thinking & 0,070 & 3,127 & 2,007 & 1,994 \\
\hline Flexible Thinking & 1,184 & 2,020 & 1,995 & 1,995 \\
\hline Original Thinking & 0,213 & 2,389 & 1,999 & 1,996 \\
\hline
\end{tabular}

According to the data from the table it is seen at the beginning of the experiment $\chi^{2} \exp <\chi^{2} t g$, and at the end of the experiment $\chi^{2} \exp >\chi^{2} t g$. In that way, in regard to development of fluency, flexibility and originality of the thinking the hypothesis $\mathrm{H}_{0}$ is reasonable at the beginning and $\mathrm{H}_{1}$ is just at the end of the experiment.

\section{Conclusion}

The experiment shows positive dynamics in students' understanding to what extent each several skills in English are important and open up new horizons to them. This confirms that the interdisciplinary approach to second-language indicated Physics teaching is not unidirectional: it is of interest not only in terms of the synergy of foreign language teaching and special subjects. Students able to present the results of the study can participate in international conferences and work with authentic scientific and technical literature gives students a range of opportunities for research activities at the international level, etc. Implementation of an interdisciplinary approach involves the development of strategic prospects both for the Faculty of Foreign Languages and the Faculty of Physics. The given interaction mechanisms can be success- 
fully extrapolated to other areas of technical profile. The relevance of digital technologies and case study in the CLIL of Physics teaching was justified from theoretical and statistical point of view. The use of digital technologies and case-study helps to implement interdisciplinary and practical orientation of educational system today. The results received are valuable for further research in order to identify organizational features of second-language integrated learning of other technical subjects and build prospects for inter-faculty cooperation.

Research results make it possible to create and implement didactic system of second-language indicated teaching of natural subjects, namely Physics:

- Transform educational system into a new model of economic growth through the technologies of accelerated second-language integrated learning of some subjects

- Narrow the gaps between education in urban and rural schools by means of IT technologies; widen opportunities to improve human resources through fast English learning

- Rise the quality of life by increasing of qualified English teachers

- Develop high-tech product based on innovative technologies in educational process

We propose to use the results of research in the process of professional training of future teachers in universities, in distance learning and in teacher training institutes.

\section{Acknowledgement}

[1] This work has been supported by Khoja Akhmet Yassawi International Kazakh-Turkish University and Kazak National Pedagogical University named after Abai. https://doi.org/10.26577/ejrs-2015-3-34

[2] Lorenzo, F., Casal, S., \& Moore, P., (2010) the effects of content and language integrated learning in European education: key findings from the Andalusian sections evaluation project. Applied linguistics 31(2), 418-442. https://doi.org/10.1093/applin/amp041

[3] Herppich, S., Praetorius, A.-K., Förster, N., Glogger-Frey, I., Karst, K., Leutner, D., Behrmann, L., Böhmer, M., Ufer, S., Klug, J., Hetmanek, A., Ohle, A., Böhmer https://doi.org/10.1016/j.tate.2017.12.001

[4] I., Karing, C., Kaiser, J., Südkamp, A. (2017). Teachers' assessment competence: Integrating knowledge-, process-, and product-oriented approaches into a competence-oriented conceptual model. Teaching and Teacher Education. https://doi.org/10.1 $\underline{016 / j . t a t e .2017 .12 .001}$

[5] Rezida, A., Fahrutdinova, I. \& Rifat, R. (2014). The Formation of Students' Foreign Language Communicative Competence during the Learning Process of the English Language through Interactive Learning Technologies (The Study on the Basis of Kazan Federal University) English Language Teaching; Published by Canadian Center of Science and Education, 7(12). https://doi.org/10.5539/elt.v7n12p36

[6] Roberto, C., Maria, R., Oriana, F. (2017). A Flipped Experience in Physics Education Using CLIL Methodology. Eurasia Journal of Mathematics 4(2). 15-20. doi:10.12973/ej mste/77044

[7] Singh, C., Belloni, M., \& Christian, W. (2006). Improving students' understanding of quantum mechanics. Physics Today, 59(8), 43. Technology Education ISSN: 1305-8223 
(online) 1305-8215 (print) $2017 \quad$ 13(10):6579-6582 doi:10.12973/ejmste/77044. https://doi.org/10.1063/1.2349732

[8] Emadi, M. F. (2013). Formation of communicative competence of future teachers of English in the foreign language education Iran (Unpublished candidate dissertation). Magnitogorsk State University, Magnitogorsk, Russian Federation.

[9] Emelyanova, O. (2004). Programs in English as one of the elements of internationalization of the University. International cooperation in education: Proceedings of the IV International Science and practical conference-SPb. SPbSPU Publishing House. 4(1). 33-37.

[10] Al-Shukri, S.H. (2004). Training with the use of intermediary language (English) in medical school: problems and prospects. International cooperation in education: Proceedings of the IV International Science and practical conference- $\mathrm{SPb}$. SPb SPU Publishing House. 4. (2).168-171.

[11] Roehl, A., Shweta, L. R., \&Gayla, J. S. (2013). The flipped classroom: An opportunity to engage millennial students through active learning. Journal of Family and Consumer Sciences 105(2), 44. DOI: 10.14307/jfcs105.2.12. https://doi.org/10.14307/jfcs105.2.12

[12] Elsakova, R., Kuzmina, N., Kochkina,D. (2019). Smart Technology Integration in the System of Bachelors' Language Training. International Journal of Emerging Technologies in Learning (iJET). Vol 14, No 15. 25-39.https://doi.org/10.3991/ijet.v14i15.10565

[13] Usembayeva I., Ramankulov Sh., Berdi D., Saparbekova G and Ualikhanova B. (2015). Procedure of Implementation the Applied Orientation of Future Teachers' Training Using ICT. American Journal of Applied Sciences. 12 (9):636-643 https://doi.org/10.38 44/ajassp.2015.636.643

[14] Leonard, D., \& Swap, W. (2010). Forstering creativity: expert solutions to everyday challenge. - Harvard University Press.

[15] Becker, H. J. (2001, April). How are teachers using computers in instruction. Paper presented at the Annual Meeting of the American Educational Research Association, Seattle, WA. 2-15

[16] Lumbantoruan, A., Christine, S. (2019). Mobile Learning in Higher Education for the Industria Revolution 4.0: Perception and Response of Physics Practicum. International Journal of Interactive Mobile Technologies (iJIM) Vol 13, No 09.4-19. https://doi.org/10.3991/ijim.v13i09.10948

[17] Angell, C., Guttersrud, O., Henriksen, E. K., \& Isnes, A. (2004). Physics: frightful, but fun. Pupils and teachers' views of physics and physics teaching. Science Education, 88(5), 683-706. https://doi.org/10.1002/sce.10141

[18] Papadakis, S. (2018). Evaluating pre-service teachers' acceptance of mobile devices with regards to their age and gender: a case study in Greece. International Journal of Mobile Learning and Organisation, 12(4), 336-352. https://doi.org/10.1504/ijmlo.2018.095130

[19] Kalogiannakis, M., \& Papadakis, S. (2019). Evaluating pre-service kindergarten teachers' intention to adopt and use tablets into teaching practice for natural sciences. International Journal of Mobile Learning and Organisation, 13(1), 113-127. https://doi.org/10.1 $\underline{\text { 504/ijmlo.2019.10016617 }}$

[20] Prather, E., Rudolph, A., \& Brissenden, G. (2011). Using Research to Bring Interactive Learning into General Education Mega-Courses. Peer Review. 13, 43-44.

[21] Amiraliev, A. (2003). Use of info communication technologies in the development of creative potential of future Physics teachers at universities. Makhachkala: Dagestan state university Publishing House.

[22] Fischer, J., \& Casey, E. (2008). LCaS - Language case studies. Teacher training modules on the use of case studies in language teaching at secondary and university level. Council of Europe Publishing. 
[23] Moldabekova, M.S., Poyarkov V., Fedorenko O.V., Asembayeva M.K. (2013). Laboratory manual on Metrology in training of specialists // Physical education in high schools. - Publishing house of Moscow Physical Society. IFRINT. 19(2), 5-6.

[24] Torrance, E. P. (2004). Teaching for Creativity. http://www.cpsb.com/research/articl es/creative-problem-solving/Teaching-for-Creative-Torrance.pdf

\section{$7 \quad$ Authors}

Sherzod Ramankulov is an associate professor at Khoja Akhmet Yassawi International Kazakh-Turkish University, Department of physics, Faculty of Natural Sciences. B.Sattarkhanov Ave, 29. Turkestan, 161200, Kazakhstan. He teaches Physics in Kazakh, English and Turkish in this University. His research interests include Creation of innovative products based on information technologies in the field of physics and their application in the development of subject-language (English) competence of physicists. E-mail: sherzod.ramankulov@ayu.edu.kz

EImurat Dosymov is PhD student at Khoja Akhmet Yassawi International KazakTurkish University., Department of physics, Faculty of Natural Sciences, B.Sattarkhanov Ave, 29. Turkestan, 161200, Kazakhstan. His research interests include improving the efficiency of the implementation of multilingual education in physics lessons by using the technology of content and language integrated learning (clil). E-mail: emu_92@mail.ru

Torebay Turmambekov is Dr.Professor at Khoja Akhmet Yassawi International Kazakh-Turkish University., Department of physics, Faculty of Natural Sciences, B.Sattarkhanov Ave, 29. Turkestan, 161200, Kazakhstan. His research interests include methodical system of formation of information and communication competence of future teachers of physics. E-mail: torebai.turmambekov@ayu.edu.kz

Dilmurad Azizkhanov is $\mathrm{PhD}$ student at Khoja Akhmet Yassawi International Kazakh-Turkish University., Department of physics, Faculty of Natural Sciences, B.Sattarkhanov Ave, 29. Turkestan, 161200, Kazakhstan. His research interests include STEM education in physics. E-mail: dima_-94_06@mail.ru

Sherzod Kurbanbekov is an associate professor at Khoja Akhmet Yassawi International Kazakh-Turkish University, Department of physics, Faculty of Natural Sciences, B.Sattarkhanov Ave, 29., Turkestan, 161200, Kazakhstan. His research interests include methods of teaching optics and nuclear physics. E-mail: Sherzod.kurbanbekov@ayu.edu.kz

Sattarbek Bekbayev is an associate professor at Khoja Akhmet Yassawi International Kazakh-Turkish University, Department of physics, Faculty of Natural Sciences, B.Sattarkhanov Ave, 29. Turkestan, 161200, Kazakhstan. His research interests include methods of teaching optics and nuclear physics. E-mail: sattarbek.bekbayev@ayu.edu.kz

Article submitted 2019-09-18. Resubmitted 2019-11-07. Final acceptance 2019-11-08. Final version published as submitted by the authors. 